\title{
Post-divorce representations of marital negotiation during marriage predict parenting alliance in newly divorced parents
}

\author{
Diogo Lamela* and Bárbara Figueiredo
}

\author{
School of Psychology, University of Minho, Braga, Portugal
}

(Received 19 April 2010; final version received 6 December 2010)

\begin{abstract}
Literature demonstrates that marital and co-parenting subsystems are intercorrelated and have autonomous functions in the family system. This study explored representations of marital negotiation strategies for conflict resolution during marriage and parenting alliance relationship after divorce, using data from Portuguese newly divorced parents. In multiple regression analysis, representations of marital negotiation strategies for conflict resolution during marriage used by ex-spouses predict positive parenting alliance relationship after divorce. These results suggest that representations of pre-divorce marital relationship influence positively current interparental relationship regarding child rearing after marital dissolution. Implications for clinical interventions are also discussed.
\end{abstract}

Keywords: negotiation; marriage; divorce; parenting alliance; co-parenting

\section{Introduction}

Parenting alliance, or co-parenting relationship, is defined as the reciprocal and joint involvement of both parents in children's education and welfare (Feinberg, 2003; Lamela, Nunes-Costa, \& Figueiredo, 2009). Conceptually, the co-parenting relationship focuses on interparental interactions regarding adults' roles and expectations as parents (McConnell \& Kerig, 2002). In this line, previous work of Weissman and Cohen (1985) defined four attributes of positive parenting alliance: (1) each parent invests in the child, (2) each parent values the other parent's parenting, (3) each parent values the other parent's involvement in the child's life and (4) both parents wish for communication with each other about child matters.

Maccoby, Depner and Mnookin (1990) developed a categorical typology of coparenting relationship after divorce. For these authors, co-parenting does not end in the shared responsibility towards children's upbringing. It also means parents' effective cooperation in the process of decision making as well as each one absorbing those educational decisions into their own individual relationship with the children. In this sense, Maccoby et al. found empirically four post-divorce co-parenting patterns. Cooperative co-parenting (26\% of the assessed parenting dyads) was defined as quality interactions between parents, guided by regular communication about the children and characterized by minimal levels of conflict and non-existence

*Corresponding author. Email: dlamela@ese.ipvc.pt 
of the relationship's mining strategies that each parent maintains individually with the children. Cooperative co-parenting requires unity and symmetry in both parents' parenting planes (Stright \& Neitzel, 2003), in which they act as a real team in conducting children's education, both from an instrumental and an emotional point of view. Moreover, conflicted co-parenting was described by the regularity of parents' communication, however, this communication is characterized by high levels of conflict, hostility, criticism and competition. Due to their position as adversaries, attempts of an effective co-parenting work are hampered. In the disengaged co-parenting pattern, each parent is involved in the life of the children, however, this is not a concerted involvement between the parents. In this pattern, a parallel parenting is present, expressed by a rudimentary communication about their children's educational issues. Finally, the mixed co-parenting was described as a combination between co-parent's attempts to educational coordination and regular discussion of matters related to the children's welfare and also maintenance of high levels of interparental conflict (Maccoby et al., 1990).

Parenting alliance research has also demonstrated that although marital and parenting alliance processes are dynamically intercorrelated, they are autonomous dimensions of adults' intimate relationship (Morrill, Hines, Mahmood, \& Córdova, 2010; van Egeren, 2004). Additionally, previous empirical work has demonstrated that parenting alliance is a major explicative dimension of family and child functioning independent of the family structural configuration (Feinberg, 2003; Whiteside, 1998). For example, in intact families, marital quality and lower family stress have been documented as main predictors of positive parenting alliance (e.g. Belsky, Crnic, \& Gable, 1995; Schoppe-Sullivan, Mangelsdorf, Brown, \& Sokolowski, 2007), while satisfaction with post-divorce financial arrangements, forgiveness and parents' psychological adjustment were found as significant predictors of positive parenting alliance in divorced parents (e.g. Bonach, 2005). Gable, Crnic and Belsky (1994) hypothesized that parenting alliance is a main family process that explains the causal interrelations between interparental relationships, parenting practices and styles and children's adjustment. This mediator value of parenting alliance may specify how and why marital functioning has impact, directly on parenting and indirectly on children's adjustment (Lamela, Nunes-Costa, \& Figueiredo, 2009). In this line, parenting alliance had a mediating effect on the association between marital relationship and parent-child relationship and also explains directly and indirectly children's adjustment, both in families with married and divorced parents (e.g. Kolak \& Vernon-Feagans, 2008; Margolin, Gordis, \& John, 2001; Whiteside \& Becker, 2000).

Literature has shown that therapy with families with divorced parents should reorganize interparental relationship regarding child care and promote the separation of past marital relationship from present parenting alliance relationship (Lamela, Castro, \& Figueiredo, 2010; Madden-Derdich, Leonard, \& Christopher, 1999). Given this assumption, we assume that marital processes before divorce can affect negatively family and child adjustment.

Although research is increasingly focusing on the connection between marital interactions and parenting alliance relationship, it has tended so far to focus only on how disruptive processes of marital relationship have negative effects on postdivorce parenting alliance and child adjustment (e.g. Hardesty, Khaw, Chung, \& Martin, 2008). 
Due this fact, little is known about how specific marital negotiation strategies could have impact on parenting alliance after divorce. Marital negotiation is defined as the use of rational argumentation, positive affect exchanges or expression of caregiving and respect as strategies for problem solving between partners (Paiva \& Figueiredo, 2006). Taking into account the interdependence of autonomous dimensions of marital and parenting alliance in married couples, it is plausible to expect that these marital negotiation strategies during marriage could be transported to parenting alliance after divorce, having important consequences on clinical intervention with families with divorced parents. However, to our knowledge no previous study has tested consistently this hypothesis.

Using a simple methodological and analytic strategy, our study aims to investigate whether representations of marital negotiation strategies for problem solving during marriage predict parenting alliance quality after divorce, in a sample of newly divorced parents.

\section{Methods}

\section{Participants}

A sample of newly divorced parents ( $n=62,58 \%$ mothers) who had officialised their divorce participated in the study. The mean age was 37.63 ( $S D=7.05$, range $=28-55$ years). The sample was well educated, with $55 \%$ of the parents holding a university degree and $22.9 \%$ with 12 years of education. Overall, parents in the sample had been divorced for an average of five months. The mean length of marriage was 10.03 years $(S D=5.98$, range $=1-24$ years $)$ and couples were separated 5.5 months $(S D=7.55$, range $=0.3-6$ months $)$ prior divorce legalization. The average number of children reported was $1.4(S D=0.57)$ and children's mean age was 8.34 years $(S D=6.4$, range $=1-15)$.

\section{Measures}

Representations of marital negotiation during marriage

Representations of marital negotiation during marriage were measured with the revised Conflict Tactics Scales (CTS2: Straus, Hamby, Boney-CcCoy, \& Sugarman, 1996). With 78 items, the CTS2 assesses the degree of prevalence and chronicity to which intimate partners make use of psychological aggression, physical assault, sexual coercion and injury in their relationship to deal with conflicts. These four scales comprise two subscales, each assessing minor and severe forms of violence. The CTS2 also evaluates the extent of positive tactics (negotiation scale) in dealing with marital disagreements. All the scale items are developed in pairs (what the participant did and what the partner did); 39 items request participants to inform how many times in the past year they perpetrated specific acts upon his/her intimate partner and the other 39 items measure the number of times their intimate partners behaved the same way towards participants (Straus, Hamby, \& Warren, 2003). Each item is rated on an eightpoint scale: 1 (1 time in past year), 2 (2 times in past year), 3 (3-5 times in past year), 4 (6-10 times in past year), 5 (11-20 times in past year), 6 (more than 20 times in past year), 7 (not in the past year but it did happen before) and 0 (this has never happened).

The Negotiation scale consists of two subscales: the cognitive subscale (three pairs of items) measures settlement strategies in marital conflict and the emotional 
subscale (three pairs of items) assesses the level of positive affect, care and respect expressed in marital conflict resolution. In this study, items of the negotiation subscales were adapted to divorced participants. Sample items of the cognitive subscale include "I explained my side of disagreement to my ex-partner" and "My expartner explained his or her side of a disagreement to me" and sample items of the emotional subscale comprise "Showed respect for my ex-partner's about an issue" and "My ex-partner showed respect for my feelings about an issue". Representations of negotiation in intimate partner relationship during marriage were tabulated based on participants' reports of the total ever occurred cognitive and emotional negotiation strategies by them and by their ex-partner, from the negotiation scale of the CTS2 (Straus et al., 2003). The Portuguese version of the CTS2 has demonstrated good construct validity as well as adequate internal consistency in all scales, with exception of one scale (Cronbach's alpha ranging from 0.78 for the injury scale to 0.50 for the sexual coercion scale) (Figueiredo \& Paiva, 2008; Paiva \& Figueiredo, 2006).

\section{Parenting alliance}

Parenting alliance was assessed with the Parenting Alliance Measure (PAM: Abidin $\&$ Konold, 1999). This 20-item measure provides an assessment of the parent's perspective about cooperation and respectful interaction between parenting dyad. The PAM was also designed to assess parenting dyad communication regarding parenting styles and practices, mutual commitment concerning child raising issues and, finally, parent's understanding of the other parent's parenting difficulties and strengths. This measure evaluates exclusively dimensions of co-parenting alliance, which enables its use with divorced parents. The PAM is theoretically based on Weissman and Cohen's (1985) parenting alliance characteristics described above. Items on the PAM are rated on a five-point Likert scale $(1=$ strongly disagree, $5=$ strongly agree) and summed together to produce a total score. Higher scores in the scale reflect higher levels of parenting alliance. Sample items include "My child's other parent and I communicate well about our child" and "I believe my child's other parent is a good parent". A similar factorial structure of the American original version was obtained in the Portuguese version of the PAM, with excellent values of internal consistency $(\alpha=94$ for mothers, $\alpha=90$ for fathers and $\alpha=92$ for a combined sample) (Lamela, Castro, Nunes-Costa, Bianchi-Aguiar, \& Figueiredo, submitted). Validity studies demonstrate that the PAM scale is negatively associated with children's social skills and psychosocial adjustment problems, parenting stress and family and marital dysfunction (Konold \& Abidin, 2001).

\section{Procedure}

Parents were recruited at the Register Office $^{1}$ of a Portuguese city. In the Register Office facilities, parents were contacted in person by the researchers. After being informed about the research goals, parents were invited to participate. Those parents who agreed to participate signed an informed consent and provided some sociodemographic information (e.g. name, phone number and address). Participants were included in the study if they had at least one child. They received the questionnaires packet by mail with a prepaid return envelope. Participants were not financially compensated. A total of 78 packets with questionnaires were sent out, of which 62 were returned $(79 \%)$. 


\section{Data analyses}

Firstly, Student's $t$-tests for independent samples were conducted in order to examine gender differences in PAM score and Negotiation CTS2 scales. Secondly, Pearson correlations were performed to analyze associations between study variables. Finally, to test the hypothesis that representations of negotiation strategies by ex-partner and by self during marriage would predict greater parenting alliance of newly divorced parents, we performed one multiple linear regression analysis.

\section{Results}

Preliminary analyses showed no gender differences in the PAM score, $t(60)=1.33$, $p=17$, Negotiation CTS2 scale by ex-partner, $t(60)=-.68, p=49$, and Negotiation CTS2 scale by self, $t(60)=-.36, p=72$. Additionally, correlation values between analyzed variables in this study are present in Table 1. Both representations of marital negotiation during marriage by ex-partner and by self were moderately and highly correlated, respectively, with post-divorce parenting alliance.

In the multiple regression analysis, we included scale's total score of representation of negotiation during marriage by ex-partner and scale's total score of representation of negotiation during marriage by self as predictors. This model of two predictors accounted for $28 \%$ of variance $\left(\mathrm{R}^{2}=28\right)$, in which representation of marital negotiation strategies during marriage by ex-partner $(B=5.71$, $p<.01)$ was the only significant predictor of the post-divorce parenting alliance (Table 2).

\section{Discussion}

Marital relationship during marriage is considered to have a significant function in post-divorce parenting alliance relationship. However, previous research has been concentrated on measuring and explaining the impact of marital disruptive and conflict interactions on parenting alliance relationship after marital dissolution. Little is known about how positive and adjusted strategies of problem resolution in marriage and representation of those may predict cooperative and communicative parenting alliance relationship after divorce. To clarify this possible connection, the present study tested whether representation of marital negotiation strategies used by the ex-partner during marriage and representation of marital negotiation strategies used by self during marriage were predictors of post-divorce parenting alliance relationship. Results indicated that representation of marital negotiation strategies during marriage by ex-partner predicted post-divorce parenting alliance relationship, attesting to the significance of positive prior divorce between marital dyad for later

Table 1. Pearson correlations between post-divorce parenting alliance and variables for representations of marital negotiation during marriage.

\begin{tabular}{lccc}
\hline & 1 & 2 & 3 \\
\hline 1. Post-divorce parenting alliance & - & - & - \\
2. Representation of marital negotiation by ex-partner & $.45^{* *}$ & - & - \\
3. Representation of marital negotiation by self & $.30^{*}$ & $.81^{* *}$ & - \\
\hline
\end{tabular}

Notes: ${ }^{*} p<.05 .{ }^{* *} p<.001$. 
Table 2. Predictors of post-divorce parenting alliance.

\begin{tabular}{|c|c|c|}
\hline \multirow[b]{3}{*}{ Variable } & \multirow{2}{*}{\multicolumn{2}{|c|}{$\frac{\text { Post-divorce parenting alliance }}{\text { Model } 1}$}} \\
\hline & & \\
\hline & $B$ & $95 \% \mathrm{CI}$ \\
\hline $\begin{array}{l}\text { Representation of marital negotiation by ex-partner } \\
\text { Representation of marital negotiation by self } \\
R^{2} \\
F\end{array}$ & $\begin{aligned} & 5.71 * \\
- & 1.99\end{aligned}$ & $\begin{aligned} & 1.28,10.13 \\
- & 7.86,3.87 \\
* & \end{aligned}$ \\
\hline
\end{tabular}

Notes: $\mathrm{CI}=$ confidence interval. Main entries are unstandardized coefficients; ${ }^{*} p<.01$.

interparental relationship. Representation of marital negotiation strategies during marriage by self does not predict post-divorce parenting alliance.

The finding that representation of marital negotiation strategies during marriage by ex-partner predicted post-divorce parenting alliance relationship is consistent with the theoretical assumption that marital and co-parenting (i.e., parenting alliance) subsystems are autonomous and intercorrelated (Feinberg, 2003). This finding is also partially consistent with previous empirical research about the effects of a family transition on the connection between marital processes before the transition and parenting alliance relationship after transition, more specifically the transition to parenthood (e.g. Menezes \& Lopes, 2007; van Egeren, 2004). It was surprising that only parents' representation of ex-partner negotiation strategies during marriage predict a greater parenting alliance between ex-spouses after divorce. However, results showed that representation of negotiation strategies by self was correlated with post-divorce parenting alliance. We consider that these results may be explained by the possible use of negotiation strategies (e.g. behavioral strategies and use of positive affect in conflict resolution) in solving parenting divergences regarding children's education and welfare issues. In other words, negotiation strategies during marriage, or representations of those strategies, may be transported to solve interparental disagreements and therefore promote positive post-divorce parenting alliance. We hypothesize that a cooperative, a positive communicative, a respectful and caring post-divorce parenting alliance are product of a selection of effective strategies for dealing with potential conflicts and that these strategies have most probably been adopted during marriage. In this line, parenting dyads that used emotional and cognitive negotiation strategies during marriage will continue applying them after divorce, more specifically in co-parenting interactions that are, for the majority of divorced parents, the only sphere of contact between ex-spouses.

In spite of its contributions to the field, our study should be analyzed with some caution. On the one hand, even though our results confirm our research hypothesis, data about representations of marital negotiation during marriage and parenting alliance were collected only after divorce. A more extensive portrait of marital negotiation during marriage effects on post-divorce parenting alliance would be possible with a longitudinal design that would examine the interrelations between the study's variables either during marriage or after divorce. Additionally, our results are circumscribed to non-litigant new divorced parents. We think that different results between representations of marital negotiation during marriage and postdivorce parenting alliance might be found with litigant divorced parents. 
Regardless of these precautions in the interpretation of findings, this study offers some implications for clinical practice. Firstly, therapists should have in mind that positive marital problem solving strategies during marriage are a main contributor for parenting alliance relationships after divorce. Divorce is a major stressful life event during adulthood. In therapy, sometimes it is very clear that divorced parents may have difficulties in separating parenting alliance from marital roles during this family transition. Parents have to go through a relationship grieving process, as much as they need to renegotiate how to take care of their child(ren) and promote family reorganization and adjustment (Rogge, Bradbury, Hahlweg, Engl, \& Thurmaier, 2006). Therapeutic processes should explore and facilitate this adjustment to family boundaries and promote behavioral, emotional and cognitive cooperation in parenting alliance as a main intervention goal.

Secondly, the dissolution of the marital subsystem that divorce implies does not mean the dissolution of the family itself. Family relationships are maintained after divorce, through new structural, communicational and interactional configurations (Nunes-Costa et al., 2009). Research has shown that marital conflict during divorce may distort parents' perspectives about parenting alliance quality and functionality. Therefore, our results confirm that therapists should map both cognitive and emotional negotiation strategies for conflict resolution during marriage and optimize them taking account the new family stage. Consequently, based on these findings it may be recommended that therapists assess and map parents' conflict resolution strategies during marriage. This clinical assessment may give information about the types, history and extension of conflict, cognitive and emotional strategies of coping and solving marital conflict used by the parenting dyad. These clinical details could assist therapists in understanding if post-divorce parenting alliance difficulties are created for non-existence in the parenting dyad's history of a repertoire of effective negotiation strategies or if those strategies were acquired and applied during marriage and divorce events are just interfering in their application in post-divorce period. Therefore, this collected information will influence the options given for the treatment plan. This is a very relevant clinical approach for therapy with families with divorced parents.

\section{Acknowledgements}

This study was supported by a PhD fellowship to first author by the Portuguese Foundation for Science and Technology (SFRH/BD/43525/2008). Authors are thankful to Ana Luísa Guimarães, Ana Rita Teixeira and Lúcia Lopes for their help in data collecting.

\section{Note}

1. In Portugal, mutual consent divorces are officialised at the local Register Offices without needing court validation (almost $90 \%$ of divorces in Portugal are mutual consenting divorces).

\section{Notes on contributors}

Diogo Lamela is clinical psychology PhD student and psychotherapist at the Family Studies and Intervention Unit, University of Minho, School of Psychology (Portugal). His research and clinical practice with families with divorced parents aim to understand how divorce, as a developmental transition, can enhance positive development opportunities to parents, children and families. 
Bárbara Figueiredo is associate professor and coordinator of the Family Studies and Intervention Unit, University of Minho, School of Psychology (Portugal). Main research themes are developmental psychopathology; mothers' and fathers' psychological adjustment and couple relationship during the transition to parenthood; mother- and father-child bonding, attachment and interactions.

\section{References}

Abidin, R., \& Konold, T. (1999). Parenting Alliance Measure: Professional manual. Odessa, FL: Psychological Assessment Resources.

Belsky, J., Crnic, K., \& Gable, S. (1995). The determinants of co-parenting in families with toddler boys: Spousal differences and daily hassles. Child Development, 66, 629-642.

Bonach, K. (2005). Factors contributing to quality co-parenting: Implications for family police. Journal of Divorce \& Remarriage, 43, 79-103.

Feinberg, M. (2003). The internal structure and ecological context of co-parenting: A framework for research and intervention. Parenting: Science and Practice, 3, 95-131.

Figueiredo, B., \& Paiva, C. (2008). Versão portuguesa das Revised Conflict Tactics Scales (CTS2) [The Revised Conflict Tactics Scales, Portuguese version (CTS2)]. In M. Simões, C. Machado, M. Gonçalves, \& L. Almeida (Eds.), Avaliação psicológica (Vol. III): Instrumentos validados para a população portuguesa (pp. 101-121). Coimbra, Portugal: Quarteto Editora.

Gable, S., Crnic, K., \& Belsky, J. (1994). Co-parenting within the family system: Influences on children's development. Family Relations, 43, 380-386.

Hardesty, J., Khaw, L., Chung, G., \& Martin, J. (2008). Co-parenting relationships after divorce: Variations by type of marital violence and fathers' role differentiation. Family Relations, 57, 479-491.

Kolak, A., \& Vernon-Feagans, L. (2008). Family-level co-parenting processes and child gender as moderators of family stress and toddler adjustment. Infant and Child Development, 17, 617-638.

Konold, T., \& Abidin, R. (2001). Parenting alliance: A multifactor perspective. Assessment, 8, 41-65.

Lamela, D., Castro, M., \& Figueiredo, B. (2010). Pais por Inteiro: Avaliação preliminar de uma intervenção em grupo para pais divorciados [Full-time parenting: Preliminary evaluation of a group intervention for divorced parents]. Psicologia: Reflexão e Crítica, 23, 334-344.

Lamela, D., Castro, M., Nunes-Costa, R., Bianchi-Aguiar, M., \& Figueiredo (submitted). Psychometric properties of Portuguese version of the Parenting Alliance Measure (PAM): Studies with divorced parents. .

Lamela, D., Nunes-Costa, R., \& Figueiredo, N. (2009). Modelos teóricos das relações coparentais: Revisão crítica [Theoretical models of co-parenting relationships: Critical review]. Psicologia em Estudo, 15, 205-216.

Maccoby, E., Depner, C., \& Mnookin, R. (1990). Co-parenting in the second year after divorce. Journal of Marriage and the Family, 52, 141-155.

Madden-Derdich, D., Leonard, S., \& Christopher, S. (1999). Boundary ambiguity and coparental conflict after divorce: An empirical test of a family systems model of the divorce process. Journal of Marriage and the Family, 61, 588-598.

Margolin, G., Gordis, E., \& John, R. (2001). Co-parenting: A link between marital conflict and parenting in two parent families. Journal of Family Psychology, 15, 3-21.

McConnell, M., \& Kerig, P. (2002). Assessing co-parenting in families of school-age children: Validation of the co-parenting and family rating system. Canadian Journal of Behavioural Science, 34, 44-58.

Menezes, C., \& Lopes, R. (2007). Relação conjugal na transição para a parentalidade: Gestação até dezoito meses do bebé [Marriage in the transition to parenthood: Pregnancy until eighteen months of baby]. Psico-USF, 12, 83-93.

Morrill, M., Hines, D., Mahmood, S., \& Córdova, J. (2010). Pathways between marriage and parenting for wives and husbands: The role of co-parenting. Family Process, 49, 59-73.

Nunes-Costa, R., Lamela, D., \& Figueiredo, B. (2009). Psychosocial adjustment and physical health in children of divorce. Jornal de Pediatria, 85, 385-396. 
Paiva, C., \& Figueiredo, B. (2006). Versão portuguesa das "escalas de tácticas de conflito revisadas": Estudo de validação [The Portuguese version of the revised Conflict Tactics Scales]. Psicologia: Teoria e Prática, 8, 14-39.

Rogge, R., Bradbury, T., Hahlweg, K., Engl, J., \& Thurmaier, F. (2006). Predicting marital distress and dissolution: Refining the two-factor hypothesis. Journal of Family Psychology, 20, 156-159.

Schoppe-Sullivan, S., Mangelsdorf, S., Brown, G., \& Sokolowski, M. (2007). Goodness-of-fit in family context: Infant temperament, marital quality and early co-parenting behavior. Infant Behavior \& Development, 30, 82-96.

Straus, M., Hamby, S., \& Warren, W. L. (2003). The conflict tactics scales handbook. Los Angeles: Western Psychological Services.

Straus, M., Hamby, S., Boney-McCoy, S., \& Sugarman, D. (1996). The revised Conflict Tactics Scales (CTS2): Development and preliminary psychometric data. Journal of Family Issues, 17, 283-316.

Stright, A., \& Neitzel, C. (2003). Beyond parenting: Co-parenting and children's classroom adjustment. International Journal of Behavioral Development, 27, 31-40.

Van Egeren, L. (2004). The development of co-parenting over the transition to parenthood. Infant Mental Health Journal, 25, 453-477.

Weissman, S., \& Cohen, R. (1985). The parenting alliance and adolescence. Annals of the American Society for Adolescent Psychiatry, 12, 24-45.

Whiteside, M. (1998). The parental alliance following divorce: An overview. Journal of Marital and Family Therapy, 24, 3-24.

Whiteside, M., \& Becker, B. (2000). Parental factors and the young child's post-divorce adjustment: A meta-analysis with implications for parenting arrangements. Journal of Family Psychology, 14, 5-26. 